\title{
Recurrent Selection for Improved Germination under Water Stress in Russian Dandelion
}

\author{
Katrina J.M. Hodgson-Kratky, Olivier M. Stoffyn, and David J. Wolyn' \\ Department of Plant Agriculture, University of Guelph, 50 Stone Road East, Guelph, \\ ON N1G 2W1, Canada
}

\begin{abstract}
AdDitional INDEX wORDs. natural rubber, half-sib family selection, phenotypic selection, Taraxacum kok-saghyz
Abstract. Russian dandelion [Taraxacum kok-saghyz (TKS)] is a promising candidate for introducing natural rubber production into North America. Seeds normally germinate in a humid microenvironment, such as the thatch layer of a lawn or under a canopy of grass; however, $5 \%$ to $15 \%$ establishment is often observed on bare soil, presumably due to water stress. Phenotypic selection and half-sib family recurrent selection were conducted for three cycles to improve germination in vitro, under low osmotic potential $\left(\Psi_{\mathrm{s}}\right)$, using a polyethylene glycol (PEG) solution. Populations were then tested for establishment on bare soil in the greenhouse and field. Germination under water stress in vitro increased from $5.8 \%$ for the cycle $0\left(C_{0}\right)$ population to $40.8 \%$ and $47.8 \%$ for the $C_{3}$-phenotypic and $C_{3}$-half-sib family populations, respectively. Soil establishment in the greenhouse and field was improved up to two- and 4-fold, respectively, compared with the $C_{0}$, in two of four greenhouse experiments and three of eight field experiments. Overall, recurrent selection for germination under water stress in vitro has potential to improve establishment in the field and can be incorporated into current breeding programs to support the overall goal of creating cultivars with high-rubber yield.
\end{abstract}

Russian dandelion is a cross-pollinated, self-incompatible diploid species (Warmke, 1943) that may be grown as a source of natural rubber in North America. TKS is adapted to southern Canada and the northern United States; however, it requires domestication to be cultivated as a new crop.

Dandelion (Taraxacum sp.) seeds typically germinate and establish in a humid microenvironment protected from direct sunlight, usually in the thatch layer of lawns and pastures (Martinkova et al., 2014). The sowing of TKS seeds on bare soil, which is prone to drying, commonly results in $5 \%$ to $15 \%$ establishment (Moussavi et al., 2016). Although more than $80 \%$ establishment is achieved in greenhouses when initiating transplants, this form of propagation would not be economical for commercial production. Consequently, breeding to improve germination under water stress could result in increased germination and establishment on bare soils in the field and facilitate the domestication of this species.

Studies of germination under water stress in soil can be problematic because consistent and uniform water potentials are difficult to maintain. The use of an osmoticum in solution can simulate drought stress and provide repeatable results in controlled environments (Springer and Goldman, 2016). Of the numerous osmotica available (e.g., PEG, mannitol, sucrose, and sodium chloride), PEG has been identified as most effective because it is nontoxic and has large molecules excluded from the seedcoat pores (Hohl and Schopfer, 1991).

The use of PEG for simulating water stress is very common and has been demonstrated in many plants, such as wheat [Triticum aestivum (Blum et al., 1980)], maize [Zea mays (Khodarahmpour, 2012)], and three dandelion species (Luo and Cardina, 2012). Percent germination of Taraxacum officinale,

Received for publication 28 Oct. 2016. Accepted for publication 18 Jan. 2017. This paper is a portion of a thesis submitted by K. Hodgson-Kratky in partial fulfillment of requirements for the degree of Master of Science.

Funding was provided by the Ontario Ministry of Agriculture and Food.

${ }^{1}$ Corresponding author. E-mail: dwolyn@uoguelph.ca.
Taraxacum laevigatum, and Taraxacum brevicorniculatum seeds exposed to decreasing water potentials from 0 to -0.8 MPa diminished incrementally from $94 \%$ to $2 \%$.

Germination patterns with PEG-induced drought stress are often similar to those in soil. Percent germination and germination rate in PEG were correlated with field emergence in sunflower [Helianthus annuus (Somers et al., 1982)] and wheat (Thill et al., 1979). However, the rate was much slower in soil compared with that in PEG solutions; seeds exposed to -0.4 MPa water potential germinated $4.5 \%$ per hour in PEG and $1 \%$ per hour in soil. The increased sensitivity to water stress in soil compared with PEG solutions is likely due to low hydraulic conductivity and wetted seed contact area in the soil (Hadas and Russo, 1974).

The potential for in vitro screening methods to improve germination under water stress has been demonstrated. Two cycles of phenotypic recurrent selection at $-0.8 \mathrm{MPa}$ increased germination of sand bluestem (Andropogon hallii) nearly 2 -fold in vitro (Springer, 2011; Springer et al., 2014). In the field, establishment increased $16.4 \%$ compared with the base population (Springer et al., 2012, 2014).

In cross-pollinated crops, phenotypic (also known as mass) and family selection are common methods to improve populations (Allard, 1960). For phenotypic selection, plants are selected based on their individual phenotypes. When conducting family selection, a group of related plants is selected based on average performance. Phenotypic selection is considered a simple and easy method and allows for large populations to be screened. However, family selection is best for quantitative traits that are determined by many genes and highly affected by the environment; replication allows experimental error to be controlled and increases heritability. Furthermore, genetic gains may be increased by selecting individuals within superior families.

Seed germination under nonstress as well as stress conditions has been shown to be a quantitative trait, controlled by many loci, in several species (Czyczylo-Mysza et al., 2014; 
Foolad et al., 2007; Hayashi et al., 2008; Wang et al., 2010). Consequently, family selection may be superior to phenotypic selection for population improvement. The objectives of this research were to compare phenotypic and half-sib family recurrent selection for enhancing TKS germination under water stress in vitro, and determine if establishment could also be improved on bare soil in the field and greenhouse.

\section{Materials and Methods}

\section{Genetic materials and population formation}

TKS accessions (W6 35156, W6 35159, W6 35160, W6 35162, W6 35164, W6 35165, W6 35166, W6 35168, W6 35169, W6 35170, W6 35172, W6 35173, W6 35176, W6 35177, W6 35178, W6 35179, W6 35180, W6 35181, W6 35182, W6 35183) were obtained from the Washington State University Regional Plant Introduction Station of the Agricultural Research Service (Pullman, WA), a division of the U.S. Department of Agriculture. All accessions were planted in the field and open-pollinated seed was collected from plants which flowered with no vernalization period. Three cycles of phenotypic recurrent selection were conducted subsequently to generate an early flowering population by intercrossing the first $10 \%$ of plants to flower in a population of 1000 . Two-hundred plants from the early flowering population were grown and open-pollinated, and seed was: 1) bulked from 100 plants for phenotypic selection $\left(\mathrm{C}_{0}\right.$-phenotypic population) and 2$)$ collected individually from the remaining plants to form 100 half-sib families for family selection ( $\mathrm{C}_{0}$-family population). Seed was rubbed against a sieve with a pore size of $425 \mu \mathrm{m}$ to remove the pappus, and then shaken over an air vent to collect the heavy viable seeds.

\section{Artificial water stress}

Selection for germination under water stress was conducted in vitro. For the two methods of selection described below and experiments to estimate gain from selection, seeds were incubated in $92 \times 16-\mathrm{mm}$ petri dishes on Whatman No. 4 filter paper (GE Healthcare, Chicago, IL), and each dish contained $7 \mathrm{~mL}$ of PEG 8000 (Sigma-Aldrich, Oakville, ON, Canada) solution. Concentrations of PEG 8000 required to create a specific $\Psi_{\mathrm{s}}$ were calculated using the formula: $\Psi_{\mathrm{s}}=$ $0.129 \mathrm{C}^{2} \mathrm{~T}-14 \mathrm{C}^{2}-0.4 \mathrm{C}$, where $\mathrm{C}=$ concentration (grams per milliliter), and $\mathrm{T}=$ temperature $\left({ }^{\circ} \mathrm{C}\right)$ (Michel, 1983). A thermocouple psychrometer (PSY1 Stem Psychrometer; ICT Intl., Armidale, NSW, Australia) was used to verify the $\Psi_{\mathrm{s}}$ of the solutions.

The $\Psi_{\mathrm{s}}$ used for selection was determined based on preliminary experiments testing the effect of decreasing $\Psi_{\mathrm{s}}$ on germination. Seeds were incubated in a PEG 8000 solution with an $\Psi_{\mathrm{s}}$ of $-1.6 \mathrm{MPa}$ for the first cycle of selection; $\Psi_{\mathrm{s}}$ was increased to $-0.6 \mathrm{MPa}$ for cycle 2 to decrease germination time. In cycle $3, \Psi_{\mathrm{s}}$ was reduced to $-0.8 \mathrm{MPa}$ to maintain selection pressure on the improved populations. The fungicide, thiram, was added to the osmotic solutions at a concentration of 1.43 g. $\mathrm{L}^{-1}$ and petri dishes were wrapped with parafilm to prevent evaporative water loss.

Phenotypic recurrent selection. For phenotypic selection, 50 seeds from the $\mathrm{C}_{0}$-phenotypic population were germinated on each of 20 petri dishes, resulting in a total population of 1000 seeds. Ten petri dishes were placed in each of two replicate growth chambers for each cycle of selection. Growth chambers were set to $20{ }^{\circ} \mathrm{C}$, with a 16 -h photoperiod ( 80 $\mu \mathrm{mol} \cdot \mathrm{m}^{-2} \cdot \mathrm{s}^{-1}$ ) provided by cool-white fluorescent bulbs, and $30 \%$ relative humidity. Petri dishes were randomized within each chamber daily. Germination was recorded for each seed when radicle protrusion was observed. The first five individual seedlings to germinate from each plate in each growth chamber were selected and placed in $92 \times 16-\mathrm{mm}$ petri dishes on Whatman No. 4 filter paper with water for root development. Five selected seedlings from each of 10 plates in each of two replicate chambers resulted in 100 selected plants (selection intensity $=10 \%$ ). After $14 \mathrm{~d}$, seedlings were planted into 50-cell plug trays filled with a peat-based soil-less medium (Sunshine Mix No. 1; Sun Gro Horticulture, Vancouver, BC, Canada), then grown for $30 \mathrm{~d}$, and transplanted subsequently into $12.7 \times$ $12.1-\mathrm{cm}$ (diameter $\times$ depth) round pots. All plants were grown in a greenhouse set to $21 / 18^{\circ} \mathrm{C}$ (day/night) with a $16-\mathrm{h}$ photoperiod, produced by high pressure sodium lamps with a photosynthetic photon flux density of 50 to $70 \mu \mathrm{mol} \cdot \mathrm{m}^{-2} \cdot \mathrm{s}^{-2}$ to supplement natural light, and fertigated on alternate weeks with $20 \mathrm{~N}-3.5 \mathrm{P}-$ $16.6 \mathrm{~K}$ at a concentration of $1.5 \mathrm{~g} \cdot \mathrm{L}^{-1}$. Once flowering initiated, plants were placed inside polyethylene fabric isolation cages (Econet T; Gintec Shade Technologies, Vanessa, ON, Canada) and open-pollinated with bumblebees [Bombus impatiens (Biobest Canada, Leamington, ON, Canada)]. An equal amount of seed from each plant was bulked to create the $\mathrm{C}_{1}$-phenotypic population for the next cycle of selection. The process was repeated to generate $\mathrm{C}_{2}$ - and $\mathrm{C}_{3}$-phenotypic generations.

AMONG AND WITHIN HALF-SIB FAMILY RECURRENT SELECTION. For family selection, 50 seeds from each of 100 half-sib families of the $\mathrm{C}_{0}$-family population were incubated in each of four replicate petri dishes and two petri dishes were placed in each of two growth chambers under conditions described above. Seedlings were selected when $\approx 10$ families had $5 \%$ germination in each of the four replicate petri dishes. The first 10 families (among family selection intensity $=10 \%$ ) that achieved 5\% germination, or if many families showed 5\% germination simultaneously, those that had the highest percent germination, were selected. Within the 10 selected families, seedlings for the first two to three seeds from each petri dish replicate to germinate were selected for a total of 10 seedlings (within family selection intensity $=5 \%$ ) from each family $(100$ total seedlings). These plants were transferred to petri dishes with water, then transplanted, and open-pollinated, as described above. Seed was collected and saved separately from each plant to produce the half-sib families constituting the $\mathrm{C}_{1}$-family population for the next cycle of selection. The process was repeated to generate $\mathrm{C}_{2}$ - and $\mathrm{C}_{3}$-family generations.

\section{Response evaluation}

Seven populations $\left(\mathrm{C}_{0}, \mathrm{C}_{1}-\mathrm{C}_{3}\right.$ phenotypic, and $\mathrm{C}_{1}-\mathrm{C}_{3}$ family) were evaluated simultaneously, as described below, to estimate selection gain precisely. Seeds of all populations were regenerated to eliminate seed age as a factor affecting germination. Each population was produced by intercrossing 200 random plants in polyethylene fabric isolation cages. Seed was produced for all populations simultaneously in Jan. 2015 on separate benches within the same greenhouse to minimize bias due to environmental variation.

IN VITRO EXPERIMENT. Seeds from the seven populations were germinated on petri dishes with PEG 8000 solution with an $\Psi_{\mathrm{s}}$ of $-1.0 \mathrm{MPa}$. For each population, four replicate petri dishes, each containing 50 seeds, were incubated within each of 
four replicate growth chambers under the conditions described above. One control dish, with seeds germinated in $7-\mathrm{mL}$ double distilled $\mathrm{H}_{2} \mathrm{O}\left(\mathrm{ddH}_{2} \mathrm{O}\right)$, was incubated per population per replicate growth chamber. All petri dishes were randomized daily within each growth chamber. Percent germination was estimated daily for each treatment replicate. The experiment was repeated independently.

Field EXPERIMENT. Seeds were planted at the Simcoe Research Station (SRS), Simcoe, Ontario (lat. $42^{\circ} 51^{\prime} \mathrm{N}$, long. $80^{\circ} 16^{\prime} \mathrm{W}$, elevation $240.5 \mathrm{~m}$ ) in a split-split-plot design. Whole plots were soil-type, sand or loam, each replicated twice, where a replicate was a different site at SRS. Soil classifications at Sand Sites 1 and 2 and Loam Sites 1 and 2 were Scotland sand and Berrien sand, and Bookton sandy clay loam and Wattford sandy loam, respectively. Sub-plots were planting dates, $4 / 5$ June 2015 and 25/26 Aug. 2015. Sub-subplots were 14 treatment combinations of seven breeding populations $\left(\mathrm{C}_{0}\right.$, $\mathrm{C}_{1}-\mathrm{C}_{3}$ phenotypic, and $\mathrm{C}_{1}-\mathrm{C}_{3}$ family) grown with or without irrigation. These were replicated four times in a randomized complete block design within each site $\times$ planting date treatment combination. About $15 \mathrm{~mm}$ of water was added to each irrigated plot by passing a watering can over the soil once on the day of planting and throughout the experiment when the soil surface was visibly dry. Each sub-subplot row was $50 \mathrm{~cm}$ and planted with 100 seeds at a depth of $\approx 5 \mathrm{~mm}$; rows were spaced $76.2 \mathrm{~cm}$. Lettuce seed was coplanted with the breeding populations to mark the rows and facilitate data collection. Lettuce plants and weeds were removed manually. Establishment was counted $14 \mathrm{~d}$ after planting (DAP). The second planting in August had low establishment after $14 \mathrm{~d}$ and was also assessed at 21 DAP. Seedlings that died before the counts were not included in establishment estimates. As a control, seeds of each population were incubated in four replicate petri dishes with $\mathrm{ddH}_{2} \mathrm{O}$, as described above.

Greenhouse EXPERIMENT. Fresh seed of the $\mathrm{C}_{0}, \mathrm{C}_{3}$ phenotypic, and $\mathrm{C}_{3}$-family populations were generated to conduct the experiment. The $\mathrm{C}_{0}$ and $\mathrm{C}_{3}$-family populations were produced in Jan. 2016 and a replicate $C_{0}$ population was produced with the $\mathrm{C}_{3}$-phenotypic population in June 2016. The experiment was arranged in a split-plot design with four replicates in each of two greenhouses under the conditions described above. Whole plots were irrigation treatments (water-saturated or water-deficit) and sub-plots were the four populations $\left(\mathrm{C}_{3}\right.$ family and $\mathrm{C}_{0}$-family control, $\mathrm{C}_{3}$-phenotypic and $\mathrm{C}_{0}$-phenotypic control). The experiment was repeated independently; the first and second experiments were planted on 30 June and 12 July 2016, respectively. Each treatment combination replicate consisted of 50 seeds planted in a $12.7 \times 12.1-\mathrm{cm}$ round pot filled with a dry peat-based medium (Sunshine Mix No. 5, Sun Gro Horticulture) at a depth of $3 \mathrm{~mm}$. Irrigation treatments were accomplished by passing a hose with a water breaker attachment (Ultra-soft Redhead; Dramm, Fenwick, ON, Canada) over whole plots where one pass was equivalent to $\approx 5 \mathrm{~mm}$ of raw water. Water-saturated treatments were irrigated daily with $30 \mathrm{~mm}$ of water and water-deficit treatments were given $30 \mathrm{~mm}$ of water on the day of planting and $10 \mathrm{~mm}$ every $2 \mathrm{~d}$, which ensured that the soil surface dried between waterings. The number of established seedlings was counted daily. For each population, a control petri dish, as described above, was placed in each replicate greenhouse.

SEED MASs. To determine the effect of selection on seed mass, 100 -seed weight was measured for the $C_{0}$ and $C_{3}$ populations.
Seed was produced independently in Jan. 2015 and 2016, and June 2016 for some or all of the populations as described above. Three replicate seed increases were obtained for the $\mathrm{C}_{0}$, and two for the $\mathrm{C}_{3}$-family and $\mathrm{C}_{3}$-phenotypic populations.

\section{Statistical analyses}

Data were fit to a generalized linear mixed model using PROC GLIMMIX in SAS (version 9.3; SAS Institute, Cary, $\mathrm{NC}$ ). The analysis of variance (ANOVA) for the in vitro experiment considered the effect of population as fixed and the effects of experiment and block nested within experiment as random. For the field experiment, the fixed effects were irrigation, population, planting date, and soil-type and the random effects were site nested within soil-type and block nested within site. For the greenhouse experiment, the effects of population and irrigation were considered fixed and the effects of experiment, greenhouse nested within experiment and block nested within greenhouse were random. For the seed mass experiment, population was considered a fixed effect and replication was random. The assumptions of the ANOVA were tested using the Shapiro-Wilk statistic for normality of error, the Levene's test for homogeneity of error, and by visual analysis of residual plots for random distribution of error. Data with heterogeneous error were fit to a heterogeneous error model. Non-Gaussian data that could not be corrected with this model were analyzed using the Gauss-Hermite Quadrature method specified with a beta distribution and complimentary log-link (Bowley, 2015). A likelihood ratio test was used to determine if random effects differed from zero. Least square means were separated using Tukey's honestly significant difference. Regression coefficients for the response of the two selection methods in vitro were generated using PROC GLIMMIX and compared using a Student's $t$ test. Significance for all analyses was determined at $P \leq 0.05$. For each experiment, controls incubated in petri dishes with water had $\geq 90 \%$ germination; therefore, no adjustments were made to germination or establishment data to account for variation in seed lots.

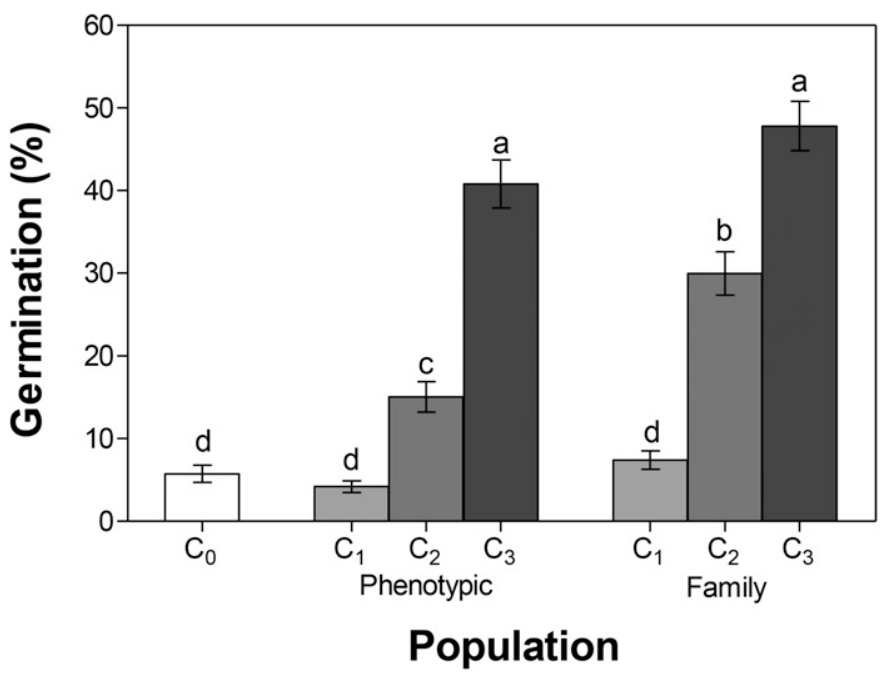

Fig. 1. Percent germination in russian dandelion populations, cycle $0\left(\mathrm{C}_{0}\right)$ to $\mathrm{C}_{3}$, $14 \mathrm{~d}$ after imbibition at $-1.0 \mathrm{MPa}$, in a polyethylene glycol 8000 solution. Populations were subjected to three cycles of phenotypic or half-sib family recurrent selection for germination under low water potential in vitro. Means $(\mathrm{n}=32)$, pooled over experiments, are presented \pm SE; letters indicate differences among all populations according to Tukey's honestly significant difference $(P \leq 0.05)$. 


\section{Results}

IN VITRO EXPERIMENT. The ANOVA indicated the effect of experiment and its interaction with population were not significant for percent germination $14 \mathrm{~d}$ after imbibition (DAI) at $-1.0 \mathrm{MPa}$, therefore data were pooled over the two experiments. The fixed effect of population was significant.

Both phenotypic and half-sib family recurrent selection increased percent germination under water stress over three cycles (Fig. 1). Percent germination of $\mathrm{C}_{2}$ and $\mathrm{C}_{3}$ populations were greater than that of the $\mathrm{C}_{0}$, and values for $\mathrm{C}_{3}$ were greater than those of $\mathrm{C}_{2} 14$ DAI. The $\mathrm{C}_{2}$-family population had higher germination than $\mathrm{C}_{2}$-phenotypic; however, the two $\mathrm{C}_{3}$ populations did not differ.

Average gain per cycle 14 DAI in vitro, determined as the slope from regression analysis, was greater for family, $14.9 \%$, than phenotypic selection, $11.6 \%$. The former may be best to improve germination under water stress; however, significant gains are possible with the latter.

Patterns of seed germination differed among populations when incubated in water, or PEG 8000 solution with an $\Psi_{\mathrm{s}}$ of $-1.0 \mathrm{MPa}$ (Fig. 2). At 2 DAI, percent germination for seeds plated in water generally increased with advancing cycles of selection; however, differences decreased over time and all populations had greater than $95 \%$ germination $4 \mathrm{DAI}$ (Fig. 2A). Seeds incubated in PEG 8000, at $-1.0 \mathrm{MPa}$, germinated more slowly and had lower percent germination than those in water (Fig. 2A and B). Days to initiate germination at -1.0 MPa generally decreased with increasing selection cycles (Fig. 2B). The $\mathrm{C}_{3}$-family population had the earliest and most rapid germination, starting at $3 \mathrm{DAI}$, while that for the $\mathrm{C}_{3}$-phenotypic population began at 5 DAI. The $\mathrm{C}_{0}, \mathrm{C}_{1}$-phenotypic, and $\mathrm{C}_{1}$-family populations were the latest to initiate germination, beginning at 7 DAI.

Field EXPeriment. For the two planting dates, 4/5 June and 25/26 Aug., the climate during the experiments represented wet and dry periods, respectively (Fig. 3). For the June planting date, $10 \mathrm{~mm}$ of rain fell at the time of seeding (Fig. 3A). In each of the following 2 weeks, the seeds received nearly $40 \mathrm{~mm}$ of rain. For the August planting date, less than $1 \mathrm{~mm}$ of precipitation fell the day before planting and $4.4,0$, and $6.2 \mathrm{~mm}$ of

${ }^{\mathrm{z} D a y s}$ after planting. rain fell during each of the three subsequent weeks, respectively (Fig. 3B). Over the duration of the two replicate experiments, air temperature remained constant, averaging $19^{\circ} \mathrm{C}$ with a mean maximum and minimum of 24 and $14^{\circ} \mathrm{C}$,

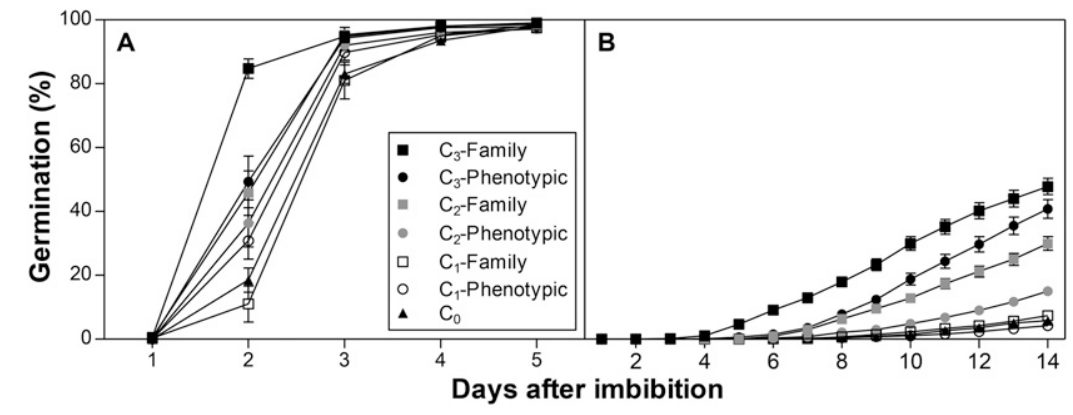

Fig. 2. Cumulative percent germination in russian dandelion populations, cycle $0\left(\mathrm{C}_{0}\right)$ to $\mathrm{C}_{3}$, incubated in $(\mathbf{A})$ double distilled $\mathrm{H}_{2} \mathrm{O}\left(\mathrm{ddH}_{2} \mathrm{O}\right)$, at $0 \mathrm{MPa}$, and (B) polyethylene glycol 8000 ( $\left.\mathrm{PEG} 8000\right)$, at $-1.0 \mathrm{MPa}$. Populations were subjected to three cycles of phenotypic or half-sib family recurrent selection for germination under low water potential in vitro. Means $\left(n=8, \mathrm{ddH}_{2} \mathrm{O}\right.$ and $n=32, \mathrm{PEG}$ $8000)$, pooled over experiments, are presented \pm SE.

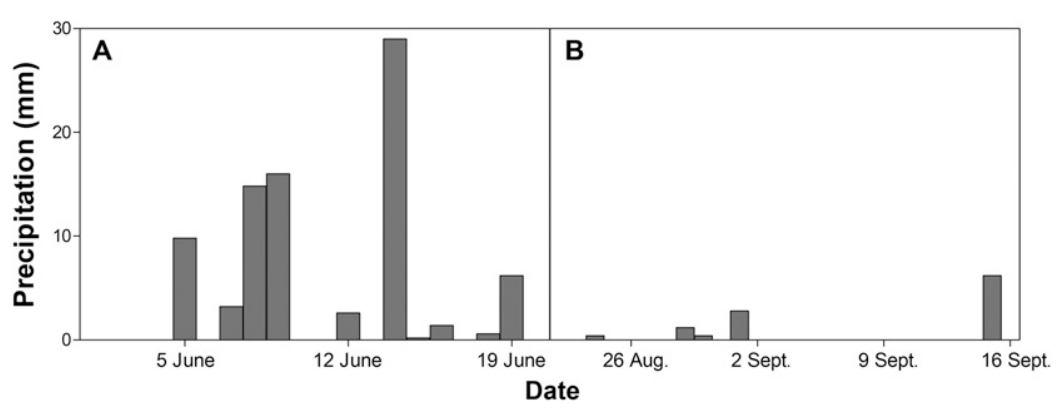

Fig. 3. Precipitation at the Simcoe Research Station, Simcoe, ON, Canada, for the duration of russian dandelion field establishment experiments planted on (A) 4/5 June 2015 and (B) 25/26 Aug. 2015.

Table 1. Fixed and interaction effects included in the PROC GLIMMIX (SAS version 9.3; SAS Institute, Cary, NC) analysis of variance models of percent establishment for russian dandelion seeds in field (Simcoe Research Station, Simcoe, ON, Canada) and greenhouse experiments.

\begin{tabular}{|c|c|c|c|c|c|}
\hline \multirow[b]{2}{*}{ Location } & \multirow[b]{2}{*}{ Planting mo. } & \multirow[b]{2}{*}{$\mathrm{DAP}^{\mathrm{z}}$} & \multicolumn{3}{|c|}{ Source of variation } \\
\hline & & & Irrigation & Population & Irrigation $\times$ population \\
\hline \multicolumn{6}{|c|}{ Field experiments } \\
\hline Sand Site $1^{\mathrm{y}}$ & June & 14 & $*$ & $*$ & NS \\
\hline \multirow[t]{3}{*}{ Sand Site 2} & June & 14 & NS & NS & NS \\
\hline & August & 14 & NS & NS & NS \\
\hline & & 21 & NS & NS & NS \\
\hline \multirow[t]{3}{*}{ Loam Site 1} & June & 14 & NS & $*$ & NS \\
\hline & August & 14 & $*$ & NS & NS \\
\hline & & 21 & $*$ & $*$ & NS \\
\hline \multirow[t]{3}{*}{ Loam Site 2} & June & 14 & NS & NS & NS \\
\hline & August & 14 & $*$ & NS & NS \\
\hline & & 21 & $*$ & NS & NS \\
\hline \multicolumn{6}{|c|}{ Greenhouse experiments } \\
\hline 1 & June & 14 & $*$ & $*$ & NS \\
\hline 2 & June & 14 & $*$ & $*$ & $*$ \\
\hline 3 & July & 14 & NS & NS & NS \\
\hline 4 & July & 14 & NS & NS & NS \\
\hline
\end{tabular}

${ }^{\mathrm{y}}$ August planting date not analyzed because almost all data points were 0 .

Ns, *Nonsignificant or significant at $P \leq 0.05$, respectively. 


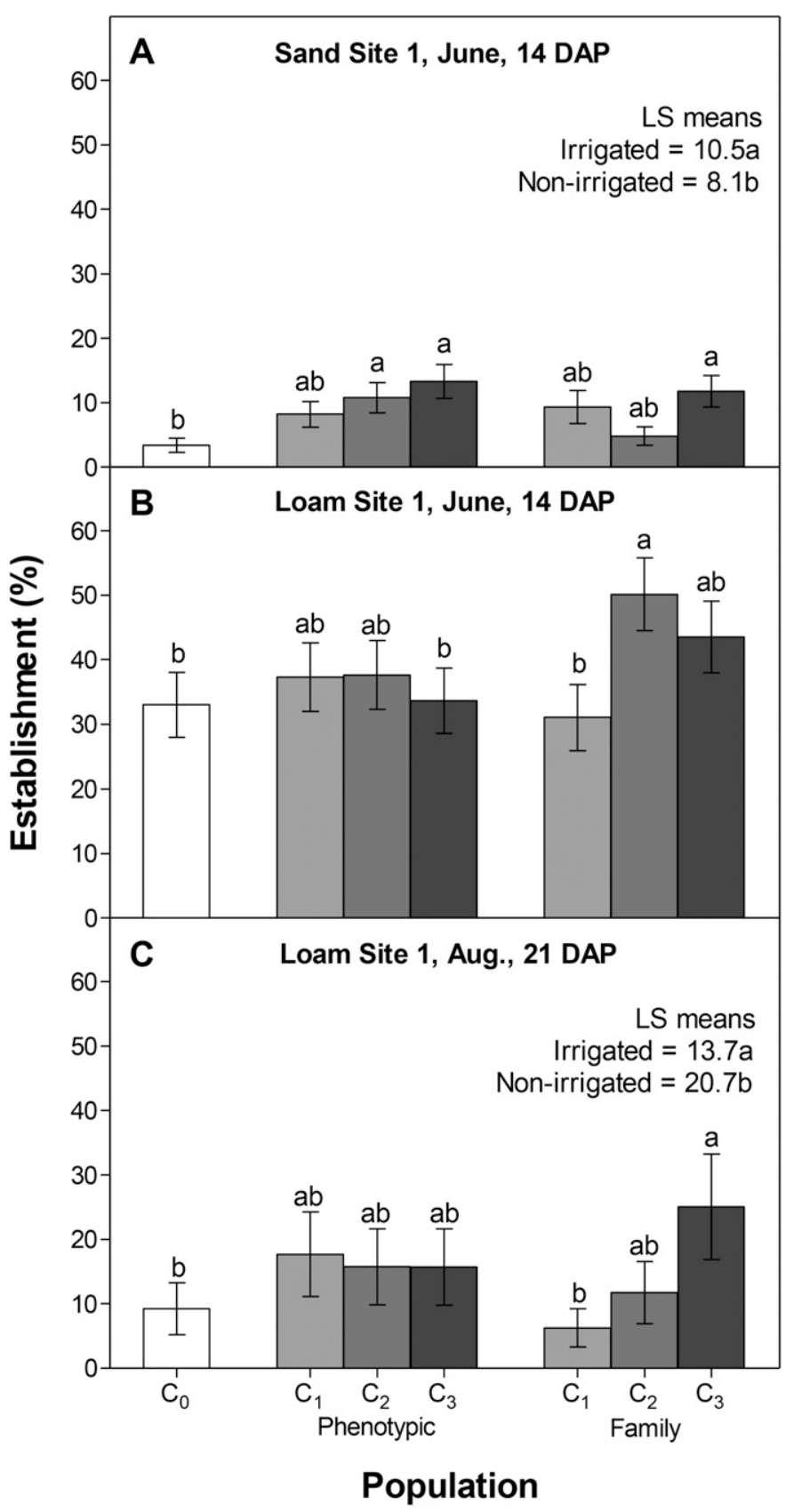

Fig. 4. Percent establishment in russian dandelion populations, cycle $0\left(\mathrm{C}_{0}\right)$ to $\mathrm{C}_{3}$, (A and B) 14 and (C) $21 \mathrm{~d}$ after planting (DAP) for (A and $\left.\mathbf{B}\right)$ June and (C) August planting dates at (A) Sand Site 1 and (B and C) Loam Site 1. Populations were subjected to three cycles of phenotypic or half-sib family recurrent selection for germination under low water potential in vitro. Means $(n=8)$, pooled over irrigation treatments, are presented $\pm S E$; letters indicate differences among all populations according to Tukey's honestly significant difference $(P \leq 0.05)$, LS means $=$ least square means.

respectively (data not shown). Relative humidity also did not change, averaging $81 \%$.

The ANOVA of the field experiment, described above with four fixed effects and two random factors, indicated significant interactions between the random effect of replicate site within soil-type and one or more fixed effects (data not shown). Consequently, the eight combinations of site within soil-type $x$ planting date were analyzed as separate experiments, with population, irrigation, and their interaction as fixed effects (Table 1).
The latter was not significant for any experiment and data were pooled over irrigation treatments. The effect of population was significant for the June planting date at Sand Site 1 and Loam Site 1 for percent establishment at 14 DAP. For the August planting, populations differed only for Loam Site 1 at 21 DAP. The effect of irrigation was significant on the June planting date at Sand Site 1 for percent establishment at 14 DAP, and on the August planting date at Loam Sites 1 and 2 at 14 and 21 DAP.

For the June planting at Sand Site 1, both selection methods improved percent establishment; the two $\mathrm{C}_{3}$ populations had more than three times the establishment of the $\mathrm{C}_{0}$ at 14 DAP (Fig. 4A). Although the $\mathrm{C}_{0}$ controls had $\approx 5 \%$ germination or establishment both in vitro and in the field, respectively, after $14 \mathrm{~d}$, the response of the $\mathrm{C}_{3}$ in the field was about half that observed in vitro (Figs. 1 and 4A). Only family selection was effective when comparing populations at Loam Site 1 for the June planting date; the $\mathrm{C}_{2}$ population was improved compared with the $\mathrm{C}_{0}$ at $14 \mathrm{DAP}$ (Fig. 4B).

Percent establishment of the $\mathrm{C}_{0}$ at 14 DAP was $3.4 \%$ and $33 \%$ at Sand Site 1 and Loam Site 1, respectively, for the June planting date, where populations differed (Fig. 4A and B). For the two sites where populations did not differ, Sand Site 2 and Loam Site 2, the $\mathrm{C}_{0}$ had $40 \%$ and $32 \%$ establishment, respectively (data not shown). Sand Site 2 was located at the bottom of a slope and remained wet from the significant rainfall during the first planting date experiment. Loam site 2 also retained moisture well. In contrast, Sand Site 1 was at the top of a slope and predisposed to drying quickly. Therefore, a lack of drought stress at Sand Site 2 and Loam Site 2 may have prevented differences from being observed between the improved and $\mathrm{C}_{0}$ control populations.

For the August planting date, improved establishment was observed only with family selection at Loam Site 1 (Fig. 4C). The $\mathrm{C}_{3}$-family population had more than twice the establishment of the $\mathrm{C}_{0}$. Percent establishment for the $\mathrm{C}_{0}$ population at Loam Site 1 was 3-fold greater for the June planting date (Fig. 4B), compared with that in August (Fig. 4C), which likely reflects differences in natural rainfall during the experiment (Fig. 3). No establishment was observed at Sand Site 1 for the August planting date while 5\% establishment was observed for the $\mathrm{C}_{0}$ at Sand Site 2 and Loam Site 2, 14 DAP (data not shown).

In some cases, irrigation had an effect on percent establishment. At the dry Sand Site 1, irrigation increased values $2.4 \%$ for the June planting date (Fig. 4A). An opposite effect was observed at the two loam sites for the August planting date 14 (data not shown) and 21 DAP (Fig. 4C); establishment was reduced an average of $4.1 \%$.

GrEenhouse EXPERIMENT. For percent establishment 14 DAP, the ANOVA indicated the 3-way interaction between greenhouse nested within experiment, population, and irrigation was significant (data not shown). Therefore, each greenhouse was analyzed as a separate experiment. Subsequent ANOVAs for percent establishment 14 DAP indicated that the effects of population and irrigation were significant in Greenhouse 1 and population, irrigation and their interaction were significant in Greenhouse 2 (Table 1).

Differences between $\mathrm{C}_{0}$ and $\mathrm{C}_{3}$ populations were observed for the water-deficit treatment in both greenhouses (Fig. 5). In Greenhouse 1, percent establishment in the $\mathrm{C}_{3}$-family population was nearly twice that of the $\mathrm{C}_{0}$, whereas the $\mathrm{C}_{3}$-phenotypic population did not appear improved (Fig. 5A). Conversely, the $\mathrm{C}_{3}$-phenotypic population had double the percent establishment 


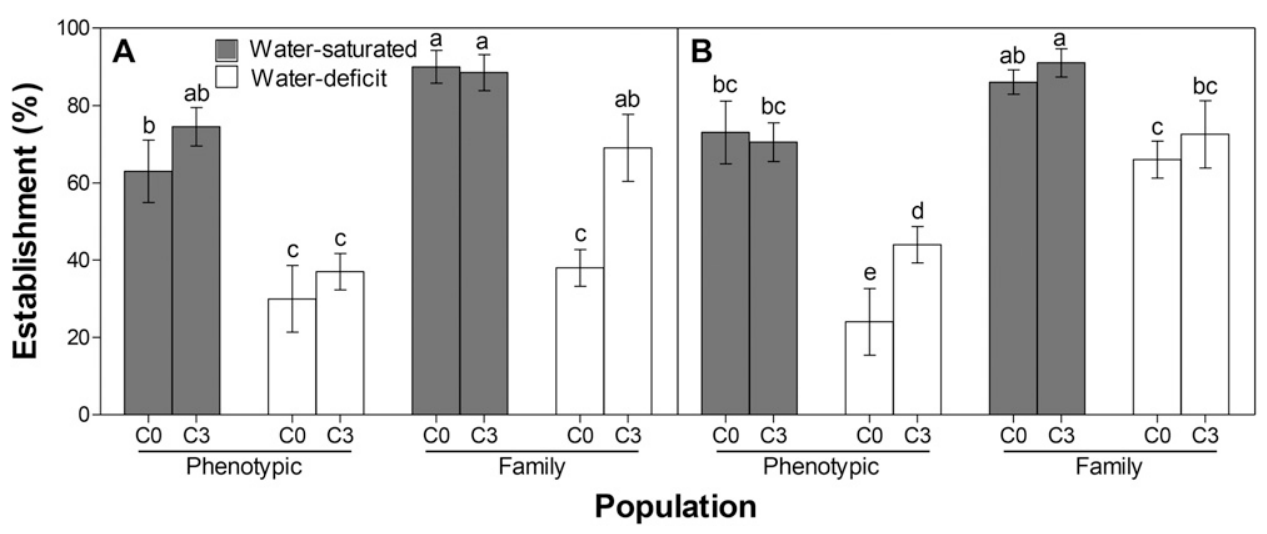

Fig. 5. Percent establishment $14 \mathrm{~d}$ after planting in russian dandelion populations, cycle $0\left(\mathrm{C}_{0}\right)$ and $\mathrm{C}_{3}$, planted in soil in Greenhouse 1 (A) and 2 (B) and given water-saturated or water-deficit irrigation treatments. Populations were subjected to three cycles of phenotypic or half-sib family recurrent selection for germination under low water potential in vitro. Means $(\mathrm{n}=4)$ are presented \pm SE; letters indicate differences among all populations according to Tukey's honestly significant difference $(P \leq 0.05)$.

compared with the $\mathrm{C}_{0}$ in Greenhouse 2 , whereas the $\mathrm{C}_{3}$-family population did not appear improved (Fig. 5B).

For the water-saturated treatment, percent establishment did not differ between the improved $\mathrm{C}_{3}$ populations and their respective $\mathrm{C}_{0}$ controls in both greenhouses (Fig. 5). The $\mathrm{C}_{3}$ - and $\mathrm{C}_{0}$-phenotypic populations had lower establishment than the $\mathrm{C}_{3}$ and $\mathrm{C}_{0}$-family populations under both irrigation treatments, indicating a seed lot effect as the seed increases for each population and control were conducted at different times. All populations, except $\mathrm{C}_{3}$-family in Greenhouse 1, had lower establishment in water-deficit compared with water-saturated treatments.

SEED MASs. One hundred seed weight of the improved and control populations did not differ and ranged from 47 to $49 \mathrm{mg}$ (data not shown). Therefore, selection had no effect on seed mass.

\section{Discussion}

Three cycles of phenotypic and half-sib family recurrent selection for germination under low water potential in vitro improved the trait more than 7-fold in TKS. In soil, under greenhouse and field conditions, establishment was improved up to 2- and 4-fold, respectively, for about half of the replicated experiments. Field establishment was optimum on loam rather than sandy soils; however, less than $50 \%$ establishment was observed when rainfall was plentiful before and after planting. Consequently, factors other than moisture may be affecting field germination and establishment. Overall, selection for germination in vitro under water stress can be a viable method to improve establishment in the field.

In vitro experiments measured germination while field and greenhouse studies estimated establishment. For the field experiment, individual seeds and seedlings were not monitored daily and germinated seedlings that died subsequently could not be determined. Consequently, field establishment not only accounts for germination but also survival. The positive responses observed with improved breeding populations suggest selection in vitro has a role for improving the germination component of establishment in the field. The effect on field survival remains to be determined.

Where differences were detected among populations in replicate field and greenhouse experiments, advanced populations from family selection differed from the $\mathrm{C}_{0}$ more often than those developed with phenotypic selection. Interestingly, the $\mathrm{C}_{3}$-phenotypic and $\mathrm{C}_{3}$-family populations rarely differed for the trait. However, average gain per cycle in vitro was greater for family than phenotypic selection. This may be, in part, due to increased selection intensity, first $10 \%$ among families, then $5 \%$ within selected families, compared with selecting $10 \%$ of individuals with phenotypic selection. Overall, selection with defined $\Psi_{\mathrm{S}}$ may provide a uniform water stress environment among petri plates to minimize experimental error and maximize genetic gain, giving positive results with both selection methods. With phenotypic selection, the ease and simplicity of conducting experiments may compensate for decreased advances compared with family selection. Increased effort to manage and replicate families, however, can maximize gains per cycle compared with phenotypic selection.

Springer (2011) and Springer et al. $(2012,2014)$ also used selection under low $\Psi_{S}$ to improve germination in sand bluestem. After two cycles of phenotypic recurrent selection, germination and establishment increased from $21.5 \%$ to $38.4 \% 7 \mathrm{DAI}$ at -0.8 MPa in vitro and from $52.5 \%$ to $61.1 \%$ in the field, respectively. Improvements in TKS reported here were greater than those observed for sand bluestem; field establishment increased up to 4-fold after three cycles of recurrent selection.

Selection appeared to have no effect on percent establishment for about half of the field and greenhouse experiments. This may be explained by large variation among replicates within certain field sites or greenhouses that reduced the detection of differences among populations. Germination or establishment experiments in soil are difficult to conduct due to inherent variation in soil structure and compaction which may affect water availability to seeds, as well as surface crusting that restricts emergence. In this study, nonuniform compaction of seedbeds produced puddles at sections of some plots after rainfall, resulting in high emergence only in those areas and inflation of experimental error. Varying moisture availability or soil properties at different sites may have also resulted in some locations with decreased water stress and diminished differences between control and improved populations.

If the detection of differences between control and improved populations at certain sites was only the result of random error, percent establishment of the $\mathrm{C}_{0}$ controls would have been significantly greater than that of improved populations at some of the sites. Observing no differences among the $\mathrm{C}_{0}$ and improved populations or only improved populations with greater establishment than the control is consistent with genetic advance from selection and large error in some experiments or overall moisture variation among sites. Continued cycles of selection (e.g., $\mathrm{C}_{6}$ ) could increase the differences between the $\mathrm{C}_{0}$ and improved populations relative to the experimental error and ultimately result in consistent, significant enhancement of establishment across multiple experiments. In the future, the methodology of the water-saturated and water-deficit greenhouse treatments could also be improved to increase precision. 
For the field experiment planted in June, when rainfall exceeded the $15 \mathrm{~mm} \cdot \mathrm{week}^{-1}$ minimum germination requirement recommended for TKS (Whaley and Bowen, 1947), establishment 14 DAP ranged from $3.5 \%$ to $40 \%$ for the $\mathrm{C}_{0}$ (Fig. 4A and B, and data not shown), whereas germination with water in petri dishes was over $90 \%$. Consequently, the $80 \mathrm{~mm}$ of rain that fell in nine events during the $14 \mathrm{~d}$ that followed planting (Fig. 3A) was insufficient to promote germination or establishment at a level similar to that observed in vitro. Soil crusting or intermittent drying of the surface, even on the loam soil, could have prevented optimum results.

Although establishment for the August planting date, during a period of drought, was less than half that of the June planting when rainfall was plentiful, a value of $25 \%$ was observed in August for the $\mathrm{C}_{3}$-family population 21 DAP. Despite the lack of natural rainfall, the observed establishment, although delayed compared with that in June, suggests TKS has potential to develop on loam soils under adverse conditions. Continued cycles of selection would be necessary to increase germination and establishment to acceptable levels.

The high and low establishment in June and August, respectively, demonstrated the importance of rainfall and sufficient soil moisture. Not surprisingly, irrigation had very little effect during the June planting, establishment increased $2.4 \%$ at 14 DAP, at the dry Sand Site 1. During the August planting, when conditions were dry, irrigation had an adverse effect, causing a reduction at some sites. This likely resulted from crusting at the soil surface, caused by rapid drying postirrigation, which prevented seedlings from emerging. Similar research conducted on cotton (Gossypium hirsutum) also found soil crusting after irrigation inhibited emergence (Nabi et al., 2001).

Conflicting results, both positive and negative correlations between seed weight and germination, have been reported in different crops (Nordon et al., 2008; Rees, 1994; Venable and Brown, 1988). Springer (2011) and Springer et al. (2014) indicated sand bluestem seed weight increased with selection. However, in this study TKS seed weight did not vary among populations generated for improved germination under water stress. Consequently, seed weight would not be a useful indirect selection criterion.

Overall, genetic gains in germination and field establishment in TKS were achieved using phenotypic and half-sib family recurrent selection under PEG-induced water stress in vitro. Complexities of assessing germination and establishment in soil are also apparent and could benefit from further study. Future research should also investigate the relationship between germination or establishment and rubber content to determine the feasibility of multitrait selection. Assuming no negative correlation is observed, in vitro selection under controlled water stress can be applied to high-rubber populations for development of elite cultivars.

\section{Literature Cited}

Allard, R.W. 1960. Principles of plant breeding. Wiley, New York, NY.

Blum, A., B. Sinmena, and O. Ziv. 1980. An evaluation of seed and seedling drought tolerance screening tests in wheat. Euphytica 29:727-736.

Bowley, S. 2015. A hitchhiker's guide to statistics in biology: Generalized linear mixed model edition. Plants et al., Guelph, ON, Canada.

Czyczylo-Mysza, I., I. Marcinska, E. Skrzypek, K. Cyganek, K. Juzon, and M. Karbarz. 2014. QTL mapping for germination of seeds obtained from previous wheat generation under drought. Cent. Eur. J. Biol. 9:374-382.

Foolad, M.R., L.P. Zhang, and P. Subbiah. 2007. Common QTLs affect the rate of tomato seed germination under different stress and nonstress conditions. Intl. J. Plant Genomics, doi: 10.1155/2007/97386.

Hadas, A. and D. Russo. 1974. Water uptake by seeds as affected by water stress, capillary conductivity, and seed-soil water contact. Agron. J. 66:643-647.

Hayashi, E., N. Aoyama, and D.W. Still. 2008. Quantitative trait loci associated with lettuce seed germination under different temperature and light environments. Genome 51:928-947.

Hohl, M. and P. Schopfer. 1991. Water relations of growing maize coleoptiles. Comparison between mannitol and polyethylene glycol 6000 as external osmotica for adjusting turgor pressure. Plant Physiol. 95:716-722.

Khodarahmpour, Z. 2012. Evaluation of drought stress effects on germination and early growth of inbred lines of MO17 and B73. Afr. J. Microbiol. Res. 6:3749-3754.

Luo, J. and J. Cardina. 2012. Germination patterns and implications for invasiveness in three Taraxacum (Asteraceae) species. Weed Res. $52: 112-121$

Martinkova, Z., A. Honek, and S. Pekar. 2014. The role of nurse plants in facilitating the germination of dandelion (Taraxacum officinale) seeds. Weed Sci. 62:474-482.

Michel, B.E. 1983. Evaluation of the water potentials of solutions of polyethylene glycol 8000. Plant Physiol. 72:66-70.

Moussavi, A., S.Z.H. Cici, C. Luocks, and R.C. van Acker. 2016. Establishing field stands of russian dandelion (Taraxacum koksaghyz) from seed in southern Ontario, Canada. Can. J. Plant Sci., doi: 10.1139/CJPS-2015-0307.

Nabi, G., C.E. Mullins, M.B. Montemayor, and M.S. Akhtar. 2001. Germination and emergence of irrigated cotton in Pakistan in relation to sowing depth and physical properties of the seedbed. Soil Tillage Res. 59:33-44.

Nordon, N., M.I. Daws, C. Antoine, M.A. Gonzalez, N.C. Garwood, and J. Chave. 2008. The relationship between seed mass and mean time to germination for 1037 tree species across five tropical forests. Funct. Ecol. 23:203-210.

Rees, M. 1994. Delayed germination of seeds: A look at the effects of adult longevity, the timing of reproduction, and population age/stage structure. Amer. Nat. 144:43-64.

Somers, D.A., S.E. Ullrich, and M.F. Ramsay. 1982. Sunflower germination under simulated drought stress. Agron. J. 75:570-572.

Springer, T.L. 2011. Recurrent selection for increased seed germination in sand bluestem (Andropogon hallii). Plant Breed. 131:198202.

Springer, T. and J. Goldman. 2016. Seed germination of five Poa species at negative water potentials. Amer. J. Plant Sci. 7:601-611.

Springer, T.L., R.L. Wynia, and G.L. Rea. 2012. Field emergence and plant density of sand bluestem lines selected for increased seed germination. Crop Sci. 52:2826-2829.

Springer, T.L., R.L. Wynia, and G.L. Rea. 2014. Registration of 'Centennial' sand bluestem. J. Plant Registrations 8:248-252.

Thill, D.C., R.D. Schirman, and A.P. Appleby. 1979. Osmotic stability of mannitol and polyethylene glycol 20,000 solutions used as seed germination media. Agron. J. 71:105-108.

Venable, D.L. and J.S. Brown. 1988. The selective interactions of dispersal, dormancy, and seed size as adaptations for reducing risk in variable environments. Amer. Nat. 131:360-384.

Wang, Z., J. Wang, Y. Bao, F. Wang, and H. Zhang. 2010. Quantitative trait loci analysis for rice seed vigor during the germination stage. J. Zhejiang Univ. Sci. B 11:958-964.

Warmke, H.E. 1943. Macrosporogenesis, fertilization, and early embryology of Taraxacum kok-saghyz. Bull. Torrey Bot. Club 70:164-173.

Whaley, W.G. and J.S. Bowen. 1947. Russian dandelion (kok-saghyz) an emergency source of natural rubber. Misc. Publ. No. 618. U.S. Govt. Printing Office, Washington, DC. 